\title{
A case series on the value of tau and neurofilament protein levels to predict and detect delirium in cardiac surgery patients
}

\author{
Thomas Sallera, , Axel Petzold ${ }^{b}$, Henrik Zetterberg ${ }^{c, d, e, f}$, Jens Kuhle ${ }^{g}$, Daniel Chappell ${ }^{\mathrm{a}}$, Vera von Dossow', Felix Klawitter', \\ Tobias Schürholzi, Christian Haglk , Daniel A Reuterj, Bernhard Zwisslera, Johannes Ehler
}

Background. Delirium following cardiac surgery is a relevant complication in the majority of elderly patients but its prediction is challenging. Cardiopulmonary bypass, essential for many interventions in cardiac surgery, is responsible for a severe inflammatory response leading to neuroinflammation and subsequent delirium. Neurofilament light protein $(\mathrm{NfL})$ and tau protein (tau) are specific biomarkers to detect neuroaxonal injury as well as glial fibrillary acidic protein (GFAP), a marker of astrocytic activation.

Methods. We thought to examine the perioperative course of these markers in a case series of each three cardiac surgery patients under off-pump cardiac arterial bypass without evolving delirium (OPCAB-NDEL), patients with a procedure under cardio-pulmonary bypass (CPB) without delirium (CPB-NDEL) and delirium after a CPB procedure (CPB-DEL). Delirium was diagnosed by the Confusion Assessment Method for the ICU and chart reviews.

Results. We observed increased preoperative levels of tau in patients with later delirium, whereas values of NfL and GFAP did not differ. In the postoperative course, all biomarkers increased multi-fold. NfL levels sharply increased in patients with CPB reaching the highest levels in the CPB-DEL group.

Conclusion. Tau and NfL might be of benefit to identify patients in cardiac surgery at risk for delirium and to detect patients with the postoperative emergence of delirium.

Key words: cardiac surgery, neuroinflammation, delirium, biomarker, neurofilaments, tau protein

Received: May 3, 2019; Revised: July 11, 2019, Accepted: August 22, 2019; Available online: September 16, 2019 https://doi.org/10.5507/bp.2019.043

(c) 2019 The Authors. This is an open access article licensed under the Creative Commons Attribution License

(https://creativecommons.org/licenses/by/4.0/).

${ }^{a}$ Department of Anaesthesiology, University Hospital, LMU Munich, Munich, Germany

bUCL Queen Square Institute of Neurology, The National Hospital for Neurology and Neurosurgery, Moorfields Eye Hospital, London, United Kingdom and Amsterdam UMC, The Netherlands

'UK Dementia Research Institute at UCL, London, United Kingdom

${ }^{d}$ Department of Neurodegenerative Disease, UCL Institute of Neurology, Queen Square, London, United Kingdom

${ }^{e}$ Clinical Neurochemistry Laboratory, Sahlgrenska University Hospital, Molndal, Sweden

${ }^{f}$ Department of Psychiatry and Neurochemistry, Institute of Neuroscience and Physiology, the Sahlgrenska Academy at the University of Gothenburg, Molndal, Sweden

${ }^{9}$ Neurologic Clinic and Policlinic, Departments of Medicine, Biomedicine and Clinical Research, University Hospital Basel, University of Basel, Switzerland

'Institute for Anesthesiology, Heart and Diabetes Center NRW, Ruhr University of Bochum, Bad Oeynhausen, Germany

'Department of Anesthesiology and Intensive Care Medicine, University Medical Center Rostock, Rostock, Germany

${ }^{k}$ Department of Cardiac Surgery, University Hospital, LMU Munich, Munich, Germany

Corresponding author:Thomas Saller, e-mail: tsaller@med.Imu.de

\section{INTRODUCTION}

Neurocognitive dysfunction after cardiac surgery is relevant in the majority of elderly patients because it impairs quality of life and often leads to the need for institutionalized care ${ }^{1}$. It remains challenging to predict which patients will suffer adverse cognitive events when undergoing cardiac surgery. The known risk factors for delirium and postoperative cognitive decline include patient frailty, preexisting cognitive impairment, mental health problems including depression and $\mathrm{age}^{2}$. A local stimulus due to surgery or trauma is believed to induce systemic inflammation followed by neuroinflammatory responses ${ }^{3}$ and an activation of microglia which leads to neuronal damage ${ }^{4}$.
This cascade is meant to be crucial in the pathogenesis of delirium. In cardiac surgery the inflammatory stimulus causing endothelial activation is induced by the artificial surface of the cardiopulmonary bypass (CPB) circuit $^{5}$ in contrast to arterial bypass surgery without $\mathrm{CPB}$ in offpump cardiac arterial bypass (OPCAB) surgery. A contact activation of the immune system is held responsible for the severe inflammatory response syndrome (SIRS) often observed after cardiac surgery under CPB and might result in the high incidence rates of delirium in these patients $^{6}$.

An increase in biomarkers of neurodegeneration has been observed in experimental and clinical studies ${ }^{6,7}$ in cardiac surgery and is associated with long-term cognitive 
impairment $t^{7,8}$. Neuroinflammation is discussed to be a critical factor in the emergence of delirium and neuroaxonal injury to the brain ${ }^{3,9}$. Few studies have focused on the development of markers of neuroinflammation and neurodegeneration in the early phase following cardiac bypass surgery ${ }^{7,10}$.

Neurofilament proteins (Nf) are specific biomarkers to detect neuroaxonal injury ${ }^{11,12}$. Neurofilament light (NfL) and heavy ( $\mathrm{NfH}$ ) chain levels were found to be increased in various diseases like multiple sclerosis (MS), amyotrophic lateral sclerosis (ALS), Morbus Parkinson or sepsis-associated encephalopathy (SAE) (ref. ${ }^{13-15}$ ). The value of tau and NfL levels to detect and monitor delirium in cardiac surgery patients is unknown. In a huge, recently published review article, Nf-L in cerebrospinal fluid was found to be useful to differentiate between neurological entities ${ }^{16}$.

We conducted a case series study of cardiac surgery patients to assess the value of tau protein (tau) and NfL (two markers of neuroaxonal injury), as well as glial fibrillary acidic protein (GFAP, a marker of astrocytic activation), in delirium.

\section{Theory}

We hypothesized that these biomarkers of neuroaxonal injury behaved differently between delirious and nondelirious patients and between patients with and without CPB procedure.

\section{METHODS}

\section{Study design}

All patient data of the present study were evaluated from a previous prospective, longitudinal observational biomarker study performed at the department of Anaesthesiology, University Hospital of Munich (LMU). Ethic approval was obtained from the local ethics committee (identifier 716-16) and the study was registered as a clinical trial (DRKS00011833). Written informed consent was obtained from all participants prior to study inclusion. Three groups of cardiac surgery patients were matched for age, gender, type of surgery, co-morbidities and baseline neurocognitive function. Inclusion criteria were age above 60 years and elective, single procedure cardiac surgery. Exclusion criteria comprised chronic renal disease (GFR $<60 \mathrm{~mL} / \mathrm{min}$ ), liver cirrhosis, preexistent mental health problems (dementia, schizophrenia, depression), pulmonary arterial hypertension, preexisting severe cognitive decline (Mini Mental Status Examination, MMSE < 24) and preoperative hemoglobin level $<10 \mathrm{~g} / \mathrm{dL}$.

Group $1(n=3)$ comprised patients undergoing an OPCAB procedure without developing delirium (OPCABNDEL). Group $2(n=3)$ included patients with CPB procedure without delirium (CPB-NDEL) and group $3(n=3)$ patients with a CPB procedure suffering post-operative delirium (CPB-DEL).

All patients received a standardized premedication with oral midazolam, anaesthesia was induced and con- tinued by continuous infusion of sufentanil $(1 \mu \mathrm{g} / \mathrm{kg}$ body weight $/ \mathrm{min}$ ) and propofol (4-6 $\mathrm{mg} / \mathrm{kg}$ body weight/h). Serum samples were taken at the day before surgery (T0), after surgery at entrance to the intensive care unit (ICU) (T1), at postoperative day 1 (T2) and at day 3 after surgery (T3) as well as at the day of discharge from hospital (4-30 days, T4).

\section{Biomarkers of neuroaxonal injury}

NfL protein levels were determined by a single molecule array (Simoa) method (Quanterix Corporation, Lexington, MA, USA) with monoclonal antibodies and calibrator (UmanDiagnostics, Umea, Sweden) at the Department of Radiochemistry, Gothenburg University, Mölndal, Sweden using a single batch of reagents, with intra-assay coefficients of variation $<10 \%$ (ref. ${ }^{17}$ ). The levels of tau and GFAP were analyzed by a commercial enzyme-linked immunosorbent assays (Fujirebio Europe, Ghent, Belgium) and with an in-house assay as described before $^{18}$.

\section{Delirium assessment}

All patients were clinically assessed for signs of delirium using the validated Confusion Assessment Method for the ICU (CAM-ICU) by nurses and physicians experienced in delirium screening and management ${ }^{19,20}$. CAM-ICU was performed at least three times per day by nurses and additionally twice per day by the study team and completed with a chart review.

\section{Statistical analysis}

The Shapiro Wilk test was used to test for normally distributed values. For not normally distributed data, we present median values (25th-75th percentile) and used the Kruskal-Wallis-Test for intragroup differences and the Friedman's test for the postoperative course of biomarker values. Categorial data were evaluated by a Chi-Squared Test and Fisher's exact test. Differences were considered to be significant with an $\alpha=5 \%(P=0.05)$. Associations were indicated by the Spearman-Rho correlation coefficient. All statistical analyses were performed in SPSS (IBM SPSS Statistics, Version 24, Armonk, NY, USA).

\section{RESULTS}

\section{Patient characteristics}

Nine patients were retrospectively evaluated in the course of cardiac surgery (see Table 1). The mean dosage of norepinephrine during anaesthesia was $0.09 \pm 0.05$ $\mu \mathrm{g} / \mathrm{kg} / \mathrm{min}$. The mean blood loss was $934 \pm 1012 \mathrm{~mL}$ (231 $\pm 72 \mathrm{~mL}$ heparinized and washed autologous blood re-transfused). No patient received homologous blood transfusion. Two patients, case \#6 and \#8, received platelet concentrates during the course of surgery. Patients were extubated after a mean ventilation time of $13.7 \pm 3.8$ $\mathrm{h}$ after ICU admission and received dexmedetomidine and propofol if additional sedation was required before the endotracheal tube could be removed. 
Table 1. Characteristics of the study group.

\begin{tabular}{|c|c|c|c|c|c|c|c|c|}
\hline \# & Sex, Age & Patient History & $\begin{array}{l}\text { Study group / } \\
\text { Type of Surgery }\end{array}$ & $\begin{array}{l}\text { MMST } \\
\text { score }\end{array}$ & $\begin{array}{l}\text { Basal } \\
\text { Nf-L }\end{array}$ & $\begin{array}{l}\mathrm{Nf}-\mathrm{L} \\
\text { factor }\end{array}$ & Delirium & $\begin{array}{c}\mathrm{LOS} \\
(\mathrm{I} / \mathrm{M} / \mathrm{H})\end{array}$ \\
\hline 1 & M, 62 & $\begin{array}{l}\text { chronic 1-coronary artery } \\
\text { disease, severe cerebral } \\
\text { macroangiopathy }\end{array}$ & $\begin{array}{l}\text { LIMA-LAD } \\
\text { (OPCAB-NDEL) }\end{array}$ & 29 & 18.5 & 1.8 & no delirium & $1 / 0 / 7$ \\
\hline 2 & M, 77 & $\begin{array}{l}\text { 3-coronary artery disease, } \\
\text { hypertension, heart failure } \\
\text { NYHA } 2\end{array}$ & $\begin{array}{l}\text { LIMA-LAD } \\
\text { (OPCAB-NDEL) }\end{array}$ & 26 & 41.2 & 1.3 & no delirium & $1 / 0 / 8$ \\
\hline 3 & F, 82 & $\begin{array}{l}\text { 2-coronary artery disease, } \\
\text { peripheral artery disease, COPD }\end{array}$ & $\begin{array}{l}\text { LIMA-LAD } \\
\text { (OPCAB-NDEL) }\end{array}$ & 29 & 47.3 & 2.0 & no delirium & $1 / 1 / 4$ \\
\hline 4 & M, 82 & $\begin{array}{l}\text { stenotic aortic valve vitium, } \\
\text { hypertension }\end{array}$ & $\begin{array}{l}\text { aortic valve repair } \\
\text { (CPB-NDEL) }\end{array}$ & 29 & 25.9 & 3.6 & no delirium & $2 / 4 / 10$ \\
\hline 5 & M, 79 & $\begin{array}{l}\text { combined aortic valve vitium, } \\
\text { hypertension, diabetes, slight } \\
\text { cerebral macroangiopathy }\end{array}$ & $\begin{array}{l}\text { aortic valve repair } \\
\text { (CPB-NDEL) }\end{array}$ & 27 & 36.8 & 3.1 & no delirium & $2 / 0 / 10$ \\
\hline 6 & M, 76 & $\begin{array}{l}\text { stenotic aortic valve vitium, } \\
\text { hypertension, intermittend } \\
\text { NYHA } 3\end{array}$ & $\begin{array}{l}\text { aortic valve repair } \\
\text { (CPB-NDEL) }\end{array}$ & 29 & 48.5 & 5.7 & no delirium & $2 / 3 / 27$ \\
\hline 7 & M, 68 & $\begin{array}{l}\text { stenotic aortic valve vitium, } \\
\text { hypertension, 1-coronary-artery } \\
\text { disease }\end{array}$ & $\begin{array}{l}\text { aortic valve repair } \\
\text { (CPB-DEL) }\end{array}$ & 28 & $<1.28$ & 29.7 & $\begin{array}{l}\text { hypoactive } \\
\text { delirium, } \\
\text { reversible on } \\
\text { haloperidol }\end{array}$ & $4 / 1 / 10$ \\
\hline 8 & M, 74 & $\begin{array}{l}\text { 3-coronary artery disease, } \\
\text { hypertension, Diabetes }\end{array}$ & $\begin{array}{l}\text { LIMA-LAD, RCA, Cx } \\
\text { (CPB-DEL) }\end{array}$ & 30 & 44.0 & 5.0 & $\begin{array}{l}\text { hypoactive and } \\
\text { hyperactive } \\
\text { delirium for } \\
4 \text { days }\end{array}$ & $1 / 3 / 13$ \\
\hline 9 & M, 74 & $\begin{array}{l}\text { combined aortic valve vitium, } \\
\text { 2-coronary artery disease, } \\
\text { hypertension, stenting for renal } \\
\text { artery stenosis }\end{array}$ & $\begin{array}{l}\text { aortic valve repair } \\
\text { (CPB-DEL) }\end{array}$ & 27 & 54.0 & 6.4 & $\begin{array}{l}\text { prolonged, } \\
\text { severe delirium } \\
\text { for } 5 \text { days }\end{array}$ & $1 / 0 / 30$ \\
\hline
\end{tabular}

The table depicts patient's basal characteristics and laboratory data, the type of surgery and outcome parameters.

NYHA New York Heart Association Functional Classification; COPD Chronic Obstructive Pulmonary Disease LIMA-LAD arterial bypass grafting on the left internal mammary Artery to the left anterior descending artery; OPCAB Off-Pump cardiac arterial bypass surgery; RCA right coronary artery; Cx circumflex branch of the left coronary artery; MMSE Mini Mental State Examiniation; Basal NfL Neurofilament Light Chain fragment before surgery and the peak concentration of NfL in the postoperative course, pg/mL; NfL factor The ratio between the basal and the peak concentration was calculated; LOS length of stay (I=ICU, M=IMC; H=Hospital);

\section{Preoperative levels of tau, NfL and GFAP}

Preoperative mean levels of tau protein were significantly increased in the CPB-DEL group $(1.567 \pm 0.252 \mathrm{ng} /$ $\mathrm{mL})$ compared to the OPCAB-NDEL group $(0.900 \pm 0.265$ $\mathrm{ng} / \mathrm{mL} ; P=0.05)$ and the CPB-NDEL group $(0.933 \pm 0.379$ ng/mL; $P=0.05$; Fig. 1 ).

Preoperative NfL levels were not significantly different between the CPB-DEL group $(71.0 \pm 38.17 \mathrm{pg} / \mathrm{mL})$ compared to CPB-NDEL patients $(37.1 \pm 11.3 \mathrm{pg} / \mathrm{mL})$ and the OPCAB-NDEL group $(35.7 \pm 15.2 \mathrm{pg} / \mathrm{mL} ; P=0.827$; Fig. 1).

Furthermore, no differences between the three groups were observed for the preoperatively measured GFAP values (Fig. 1).

\section{Longitudinal development of tau, NfL and GFAP levels after surgery}

Tau levels significantly increased several-fold in all three groups $(P=0.013)$ after surgery reaching the individual peak concentration of $16 \mathrm{ng} / \mathrm{mL}$ at T1 $(P=0.021)$ and nearly a return to basal values in all patient groups (Fig. 2a). At the first postoperative day, mean tau concen- trations were 2.9 in the OPCAB-NDEL, 2.4 in the CPBNDEL and $8.0 \mathrm{ng} / \mathrm{mL}$ in the CPB-DEL group, reflecting a 2.6, 2.4 and 5.0-fold increase from baseline, respectively.

$\mathrm{NfL}$ levels only slightly increased to an individual peak concentration of $94.3 \mathrm{pg} / \mathrm{mL}$ in the OPCAB-NDEL group ( $41 \%$ increase from baseline, peak at T3, Figure b). Within the CPB-NDEL group a stronger increase of NfL levels to a mean peak concentration of $88 \mathrm{pg} / \mathrm{mL}$ (about 2-fold increase from baseline, peak at T2) was observed. The strongest increase of NfL levels was detected in the CPB-DEL group with peak concentrations above $100 \mathrm{pg} / \mathrm{mL}$ (and several-fold mean increase from baseline $(P=0.011)$, peak at T4 $(P=0.002)$, Fig. $2 b)$.

No differences between the groups were observed for the development of GFAP levels over time $(P=0.091)$. Every patient experienced at least a distinct, almost twofold increase, with its perioperative maximum in different points of time (Fig. $2 \mathrm{c}$ ). This was not specifically related to delirium or the type of surgery. However, levels of GFAP were associated with values of NfL on postoperative day one $(\mathrm{r}=0.800 ; P=0.01)$ and at discharge $(\mathrm{r}=0.821$; $P=0.023)$. 


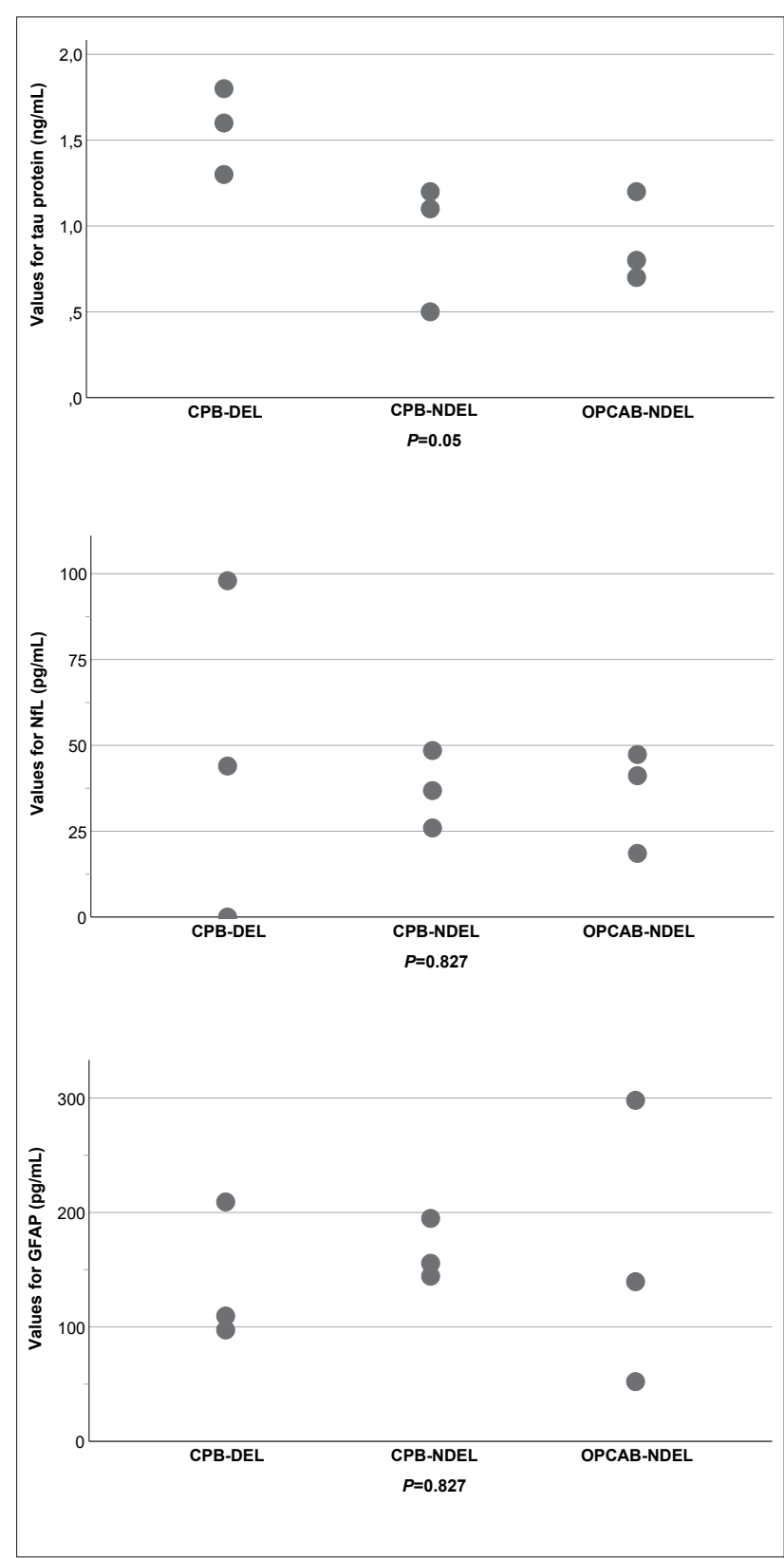

Fig. 1. Preoperative values for tau protein, NfL and GFAP.

\section{DISCUSSION}

We present a case series of nine patients undergoing cardiac surgery. All patients had comparable preoperative conditions for cognitive as well as intraoperative features and neither preexisting neurocognitive impairment nor other neurologic disease before surgery. Therefore, our data might give some important insights into the longitudinal development of biomarkers of neurodegeneration after cardiac surgery.

The idea to use biomarkers for neurodegeneration is to address two main diagnostic shortcomings in patients with delirium. First, the preoperative identification of patients at high risk for the emergence of postoperative delirium. Present tools for delirium prediction have proven to be insufficient ${ }^{21}$. Second, the early detection of delirium during the postoperative phase. Both shortcomings are highly relevant for intensivists as critically ill patients can-

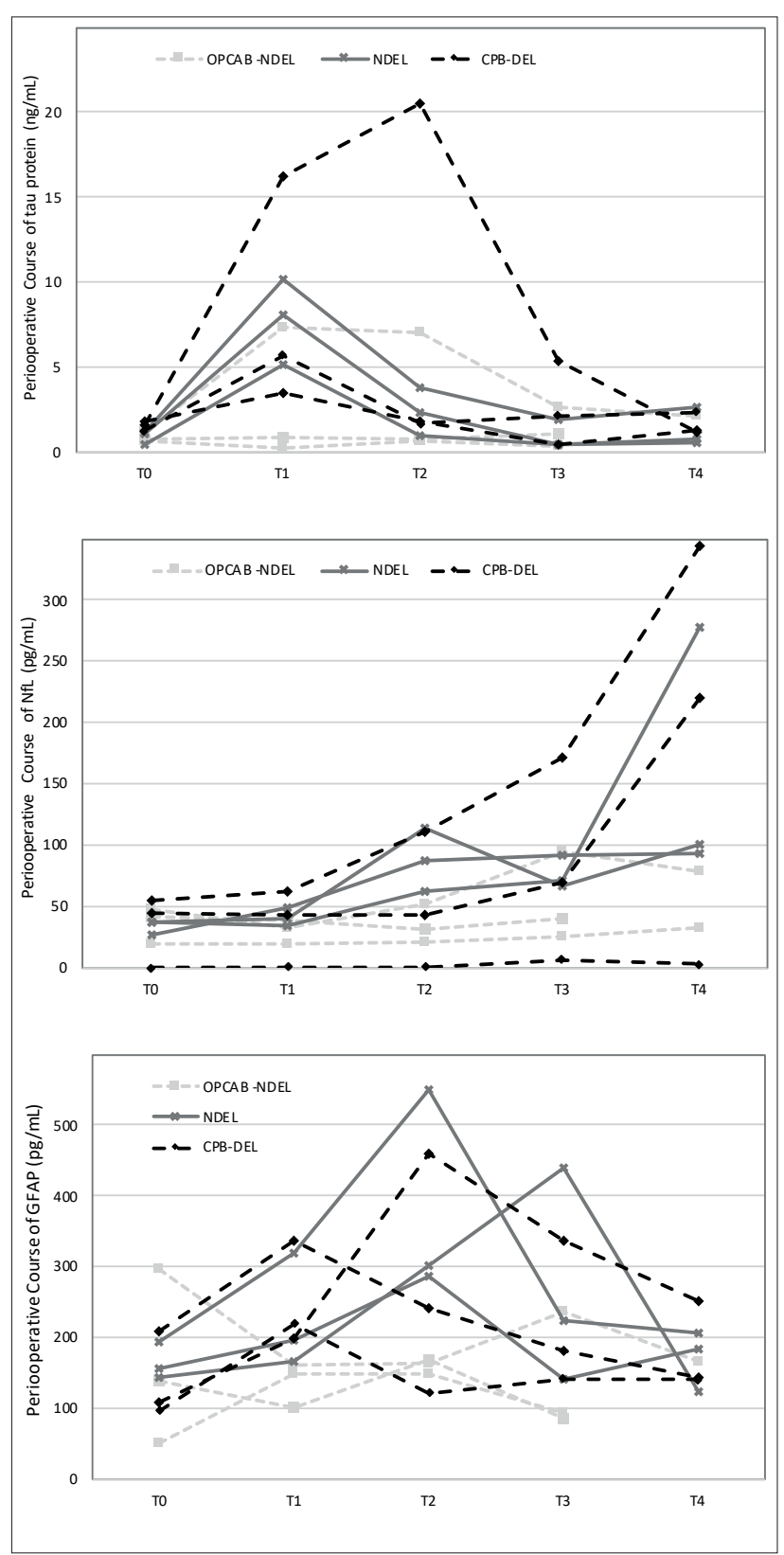

Fig. 2. Perioperative course of tau protein, NfL and GFAP.

not easily be assessed clinically for signs of delirium due to sedation or mechanical ventilation. The identification of patients at high risk for delirium might enable the clinical personnel to perform a closer delirium screening and monitoring and, if necessary, an early start of delirium treatment. This is important as the duration of delirium is associated with impaired outcome ${ }^{21}$. Given the different pathophysiological hypotheses on delirium, the biomarker guided detection of the emerging delirium and the monitoring of a present delirium might allow to discriminate between patients with a transient delirium without brain injury and patients with the emergence of structural brain damage $^{22}$. Especially these patients could profit from longitudinal biomarker measurements to perform brain imaging in a timely manner, to adapt treatment strategies and to prevent long-term neurocognitive impairment.

There are some important conclusions that can be drawn from our data. The biomarkers tau, GFAP and 
NfL showed a completely different behavior in the cardiac surgery patients of the present study. Among all three biomarkers, GFAP levels seemed to be least suitable for delirium prediction, detection and monitoring as no relevant differences were observed between the three patient cohorts. These observations correspond with previous data derived from a non-cardiosurgical cohort with no association between CSF GFAP levels and delirium ${ }^{23}$. The release of GFAP, as a structural protein of astrocytes, is usually associated with acute brain damage such as traumatic brain injury ${ }^{24}$. However, we did not notice complications like stroke or seizures leading to manifest brain injury in our patients. Results from brain imaging were not available, which is a limitation of the present study. We cannot exclude that structural brain injury was present in some of our patients. Brain imaging should be therefore part of a future study protocol.

The higher preoperative tau protein levels in patients with CPB and delirium (CPB-DEL group) compared to the two other groups suggest that tau measurements might be of value to predict postoperative delirium in cardiac surgery patients. In line with our observations, Simons et al. reported higher tau levels in patients with emerging hypoactive delirium ${ }^{25}$. We speculate that patients with higher tau levels in our study had subclinical neurological impairment that was not detected by the MMSE. This test might not have been sensitive enough to detect neurocognitive dysfunction at early stages, which advocates preoperative Tau measurements in cardiac surgery patients.

The development of the NfL was completely different to tau and GFAP (ref. ${ }^{26}$ ). The increase of NfL over time might indicate that this biomarker is relevant for the detection and monitoring of the emerging delirium. Without significant differences in the basal neurofilament levels between the three groups, the increase of NfL levels over time was much greater in patients with delirium and CPB compared to patients without delirium or OPCAB. The lower increase of NfL levels in the OPCAB-NDEL group suggests that a minor systemic inflammatory stimulus might have been induced due to the absence of $\mathrm{CPB}$ procedure. These observations support the previously discussed link between systemic inflammation and a neuroinflammatory response within the central nervous system ${ }^{9}$.

$\mathrm{NfL}$ as a specific marker of neuronal damage tended to increase at the end of our observation period. In contrast to NSE and S100B, which are known to show a decrease quickly after brain damage, NfL might better indicate neuroaxonal injury leading to cognitive decline beyond delirium. Due to the small number of participants within the present study, some longitudinal biomarker developments are not easily comprehensible. A conspicuous case was patient \#7 (CPB-DEL group), who experienced a short, but intense course of delirium. In this case, levels of NfL prior to surgery were below the level of quantification $(<1.28 \mathrm{pg} / \mathrm{mL})$. As a mathematician with an academic career, this patient was the only participant holding a university degree. Besides, he had the strongest increase in NfL levels (about factor 30). It is striking that the highest concentration of NfL in this patient was reduced until discharge by factor three. NfL levels of the other two
CPB-DEL patients increased further until discharge. The notion of a high educational standard being protective in developing delirium is controversially discussed ${ }^{27,28}$. This association might either be based on a sufficient clearing mechanism for neurotoxic substances and debris detrimental for brain functioning ${ }^{29}$ or a stronger constitution of the brain less sensitive to neurodegeneration ${ }^{4}$.

Another interesting case was subject \#6, who did not experience delirium, but had an extraordinary increase in NfL until the day of discharge. This was the only patient with a prolonged ICU stay and repeated surgery (drainage of pericardial effusion). As we did not prospectively examine this patient for delirium during the four weeks of his hospital stay, a subsyndromal delirium might have been present. Certainly, in our chart review, there was no hint on delirium.

The longitudinal development of NfL levels showed a peak concentration at the day of discharge in all patients with the exception of patient \#3 (OPCAB) and patient \#7. The hypothetical value of NfL measurements for the perception of long-term neurocognitive impairment is unclear and should be evaluated by further studies. It is imperative to collect samples in a much longer period of time than we did in our study to find the turning point of $\mathrm{NfL}$ in the perioperative course, reflecting the reversal of neurodegenerative activity following cardiac surgery which leads to cognitive decline. Other markers of neuronal damage like NSE and S100B might be useful, but previous studies were not able to give strong evidence for their value to detect and predict delirium ${ }^{30,31}$.

Those individuals having high preoperative NfL levels ( $>40 \mathrm{pg} / \mathrm{mL}$ ) experienced delirium or other complications (cases \#6, \#8 and \#9) when being exposed to CPB. One conclusion might be that the incidence of increased $\mathrm{NfL}$ reflects a higher vulnerability of the brain to exogenous triggers such as infection or CBP and might increase the risk to develop delirium. This could enable physicians in the future to adapt treatment strategies, e.g. alternative surgical (OPCAB) or anaesthesiological (regional anaesthesia) approaches to reduce the risk of delirium and to improve long-term neurocognitive patient outcome.

\section{CONCLUSION}

With the present case series, we demonstrated the potential value of tau and NfL levels to predict and detect delirium after cardiac surgery. Cardiopulmonary bypass procedure might have significant impact on the emergence of postoperative delirium represented by increasing biomarkers of neuroaxonal injury. Further prospective, well-powered studies should focus on these biomarkers in a broader time frame to thoroughly document their association with and their value for delirium.

Acknowledgement: We want to thank cand. med. Cyril Schumacher and cand. med. Eric Struck, M.D. for their contribution in performing the delirium assessments as well as Gaby Groeger as a representative for the anaesthesia lab team for their help with the management of samples. 
Author contributions: TS, JE, AP: study design; TS, DC, $\mathrm{VvD}, \mathrm{CH}$ : collection of the samples; HZ, JK laboratory analysis; TS, TSch, FK, DR, BZ, JE: data analysis and interpretation; All authors approved the manuscript.

Conflict of interest statement: None declared.

\section{REFERENCES}

1. Kotfis K, Szylińska A, Listewnik M, Strzelbicka M, Brykczyński M, Rotter I, Żukowski M. Early delirium after cardiac surgery: an analysis of incidence and risk factors in elderly ( $\geq 65$ years) and very elderly ( $\geq 80$ years) patients. Clin Interv Aging 2018;13:1061-70.

2. Berger M, Terrando N, Smith SK, Browndyke JN, Newman MF Mathew JP: Neurocognitive Function after Cardiac Surgery: From Phenotypes to Mechanisms. Anesthesiology 2018;129(4):829-51. doi: 10.1097/ALN.0000000000002194

3. Cerejeira J, Lagarto L, Mukaetova-Ladinska EB. The immunology of delirium. Neuroimmunomodulation 2014;21(2-3):72-8.

4. Merluzzi AP, Carlsson CM, Johnson SC, Schindler SE, Asthana $\mathrm{S}$, Blennow K, Zetterberg H, Bendlin BB. Neurodegeneration, synaptic dysfunction, and gliosis are phenotypic of Alzheimer dementia. Neurology 2018;91(5):e436-e443. doi: 10.1212/ WNL.0000000000005901

5. Brettner F, Chappell D, Schwartz L, Lukasz A, Kumpers $P$, Becker BF, Reichart B, Rehm M, Bruegger D. Vascular Endothelial Dysfunction during Cardiac Surgery: On-Pump versus Off-Pump Coronary Surgery. Eur Surg Res 2017;58(5-6):354-68.

6. Kraft F, Schmidt C, Van Aken H, Zarbock A. Inflammatory response and extracorporeal circulation. Best Pract Res Clin Anaesthesiol 2015;29(2):113-23.

7. Palotás $A$, Reis HJ, Bogáts $G$, Babik B, Racsmány M, Engvau L, Kecskeméti E, Juhász A, Vieira LB, Teixeira AL. Coronary artery bypass surgery provokes Alzheimer's disease-like changes in the cerebrospinal fluid. J Alzheimers Dis 2010;21(4):1153-64.

8. Reis HJ, Teixeira AL, Kálmán J, Bogáts G, Babik B, Janka Z, Teixeira MM, Palotás A. Different inflammatory biomarker patterns in the cerebro-spinal fluid following heart surgery and major non-cardiac operations. Curr Drug Metab 2007;8(6):639-42.

9. Cerejeira J, Firmino H, Vaz-Serra A, Mukaetova-Ladinska EB. The neuroinflammatory hypothesis of delirium. Acta Neuropatho 2010;119(6):737-54.

10. Hernández-García C, Rodríguez-Rodríguez A, Egea-Guerrero JJ. Brain injury biomarkers in the setting of cardiac surgery: Still a world to explore. Brain Inj 2016;30(1):10-17.

11. Gaiottino J, Norgren N, Dobson R, Topping J, Nissim A, Malaspina A, Bestwick JP, Monsch AU, Regeniter A, Lindberg RL, Kappos L, Leppert D, Petzold A, Giovannoni G, Kuhle J. Increased neurofilament light chain blood levels in neurodegenerative neurological diseases. PLoS One 2013;8(9):e75091.

12. Petzold A. Neurofilament phosphoforms: surrogate markers for axonal injury, degeneration and loss. J Neurol Sci 2005;233(1-2):183-98.

13. Ehler J, Barrett LK, Taylor V, Groves M, Scaravilli F, Wittstock M, Kolbaske S, Grossmann A, Henschel J, Gloger M, Gloger M, Sharshar T, Chretien F, Gray F, Nöldge-Schomburg G, Singer M, Sauer M Petzold A.Translational evidence for two distinct patterns of neuroaxonal injury in sepsis: a longitudinal, prospective translationa study. Crit Care 2017;21(1):262.

14. Khalil M, Teunissen CE, Otto M, Piehl F, Sormani MP, Gattringer T, Barro C, Kappos L, Comabella M, Fazekas F, Petzold A, Blennow K, Zetterberg $\mathrm{H}$, Kuhle J. Neurofilaments as biomarkers in neurological disorders. Nat Rev Neurol 2018;14(10):577-89.

15. Ehler J, Petzold A, Wittstock M, Kolbaske S, Gloger M, Henschel J, Heslegrave A, Zetterberg H, Lunn MP, Rommer PS, Grossmann A, Sharshar T, Richter G, Nöldge-Schomburg G, Sauer M. The prognostic value of neurofilament levels in patients with sepsis-associated encephalopathy - A prospective, pilot observational study. PloS One 2019;14(1):e0211184.

16. Bridel $C$, van Wieringen $W N$, Zetterberg $H$, Tijms BM, Teunissen $C E$, and the NFLG, Alvarez-Cermeno JC, Andreasson $U$, Axelsson M, Backstrom DC, Bartos A, Bjerke M, Blennow K, Boxer A, Brundin L, Burman J, Christensen T, Fialová L, Forsgren L, Frederiksen JL, Gisslén
M, Gray E, Gunnarsson M, Hall S, Hansson O, Herbert MK, Jakobsson J, Jessen-Krut J, Janelidze S, Johannsson G, Jonsson M, Kappos L, Khademi M, Khalil M, Kuhle J, Landén M, Leinonen V, Logroscino G, Lu CH, Lycke J, Magdalinou NK, Malaspina A, Mattsson N, Meeter LH, Mehta SR, Modvig S, Olsson T, Paterson RW, Pérez-Santiago J, Piehl F, Pijnenburg YAL, Pyykkö OT, Ragnarsson O, Rojas JC, Romme Christensen J, Sandberg L, Scherling CS, Schott JM, Sellebjerg FT, Simone IL, Skillbäck T, Stilund M, Sundström P, Svenningsson A, Tortelli R, Tortorella C, Trentini A, Troiano M, Turner MR, van Swieten JC, Vågberg M, Verbeek MM, Villar LM, Visser PJ, Wallin A, Weiss A, Wikkelsø C, Wild EJ. Diagnostic Value of Cerebrospinal Fluid Neurofilament Light Protein in Neurology: A Systematic Review and Meta-analysis. JAMA Neurol 2019 Jun 17. doi: 10.1001/jamaneurol.2019.1534. [Epub ahead of print]

17. Kuhle J, Barro C, Andreasson U, Derfuss T, Lindberg R, Sandelius A, Liman V, Norgren N, Blennow K, Zetterberg H. Comparison of three analytical platforms for quantification of the neurofilament light chain in blood samples: ELISA, electrochemiluminescence immunoassay and Simoa. Clin Chem Lab Med 2016;54(10):1655-61.

18. Rosengren LE, Wikkelso C, Hagberg L. A sensitive ELISA for glial fibrillary acidic protein: application in CSF of adults. J Neurosci Methods 1994;51(2):197-204.

19. Guenther U, Popp J, Koecher L, Muders T, Wrigge H, Ely EW, Putensen C. Validity and reliability of the CAM-ICU Flowsheet to diagnose delirium in surgical ICU patients. J Crit Care 2010;25(1):144-51.

20. Gusmao-Flores D, Salluh Jl, Chalhub R, Quarantini LC. The confusion assessment method for the intensive care unit (CAM-ICU) and intensive care delirium screening checklist (ICDSC) for the diagnosis of delirium: a systematic review and meta-analysis of clinical studies. Crit Care 2012,16(4):R115.

21. Saczynski JS, Marcantonio ER, Quach L, Fong TG, Gross A, Inouye SK, Jones RN. Cognitive trajectories after postoperative delirium. N Engl J Med 2012;367(1):30-9.

22. Maldonado JR. Delirium pathophysiology: An updated hypothesis of the etiology of acute brain failure. Int J Geriatr Psychiatry 2018;33(11):1428-1457. doi: 10.1002/gps.4823

23. Cape E, Hall RJ, van Munster BC, de Vries A, Howie SE, Pearson A, Middleton SD, Gillies F, Armstrong IR, White TO, Cunningham C, de Rooij SE, MacLullich AM. Cerebrospinal fluid markers of neuroinflammation in delirium: a role for interleukin-1 $\beta$ in delirium after hip fracture. J Psychosom Res 2014;77(3):219-25.

24. Böhmer AE, Oses JP, Schmidt AP, Perón CS, Krebs CL, Oppitz PP, D'Avila TT, Souza DO, Portela LV, Stefani MA. Neuron-specific enolase, $\mathrm{S} 100 \mathrm{~B}$, and glial fibrillary acidic protein levels as outcome predictors in patients with severe traumatic brain injury. Neurosurgery 2011;68(6):1624-30; discussion 1630-1621.

25. Simons KS, van den Boogaard M, Hendriksen $E$, Gerretsen J, van der Hoeven JG, Pickkers P, de Jager CPC. Temporal biomarker profiles and their association with ICU acquired delirium: a cohort study. Crit Care 2018;22(1):137.

26. Evered L, Silbert B, Scott DA, Zetterberg H, Blennow K. Association of Changes in Plasma Neurofilament Light and Tau Levels With Anesthesia and Surgery: Results From the CAPACITY and ARCADIAN Studies. JAMA Neurol 2018;75(5):542-7.

27. Oliveira FR, Oliveira VH, Oliveira IM, Lima JW, Calderaro D, Gualandro DM, Caramelli B. Hypertension, mitral valve disease, atrial fibrillation and low education level predict delirium and worst outcome after cardiac surgery in older adults. BMC Anesthesiol 2018;18(1):15.

28. Schoen J, Meyerrose J, Paarmann H, Heringlake M, Hueppe M, Berger $\mathrm{KU}$. Preoperative regional cerebral oxygen saturation is a predictor of postoperative delirium in on-pump cardiac surgery patients: a prospective observational trial. Crit Care 2011;15(5):R218.

29. Mander BA, Winer JR, Jagust WJ, Walker MP. Sleep: A Novel Mechanistic Pathway, Biomarker, and Treatment Target in the Pathology of Alzheimer's Disease? Trends Neurosci 2016;39(8):55266.

30. Schaefer ST, Koenigsperger S, Olotu C, Saller T. Biomarkers and postoperative cognitive function: could it be that easy? Curr Opin Anaesthesiol 2019;32(1):92-100.

31. Ayob F, Lam E, Ho G, Chung F, El-Beheiry H, Wong J. Pre-operative biomarkers and imaging tests as predictors of post-operative delirium in non-cardiac surgical patients: a systematic review. BMC Anesthesiol 2019;19(1):25. 